\title{
Pioneering geneticist Mary-Claire King receives the 2014 Lasker Koshland Special Achievement Award in Medical Science
}

$T$ 2014 Lasker Koshland Special Achievement Award in Medical Science has been awarded to Dr. Mary-Claire King, a pioneer in human genetics (Figure 1). Dr. King discovered the BRCA1 gene locus that underlies hereditary breast cancer; additionally, she has been instrumental in utilizing DNA sequencing to identify missing persons. In her address to the American Society for Human Genetics in 2012, Dr. King stated that "In genetics, there are hard problems and incredibly hard problems, but we do not acknowledge any unsolvable problems. The most daunting task for us is not tackling new discovery but rather integrating discovery into a meaningful social context" (1). Dr. King has consistently taken on incredibly hard problems in genetics, and her work has had a profound influence on our understanding of the genetics of human disease, on the use of DNA to advance human rights and prosecute abuses of those rights, and on our view of the frontiers in genomic technologies.

\section{Using mathematics to answer genetic questions}

Dr. King received her bachelor's degree in mathematics from Carleton College. She had initially pursued postgraduate studies in statistics at the University of California at Berkeley, but after taking a course in genetics, she transferred departments and joined Allan Wilson's lab. Dr. Wilson's research was focused on the evolutionary relationships between humans and other primate species. By comparing genes and proteins in chimpanzees with those in humans, Dr. King discovered that the two species differ in approximately $1 \%$ of their protein-coding DNA sequences, a much closer relationship than the fossil record suggested (2).

After completing her doctoral work in 1972, Dr. King moved to Santiago, Chile, for a teaching exchange program, but had to return to California after the military coup in 1973, which deposed Chilean president Salvador Allende. Nicholas Petrakis offered her a position in his laboratory at UCSF to determine why some families are severely

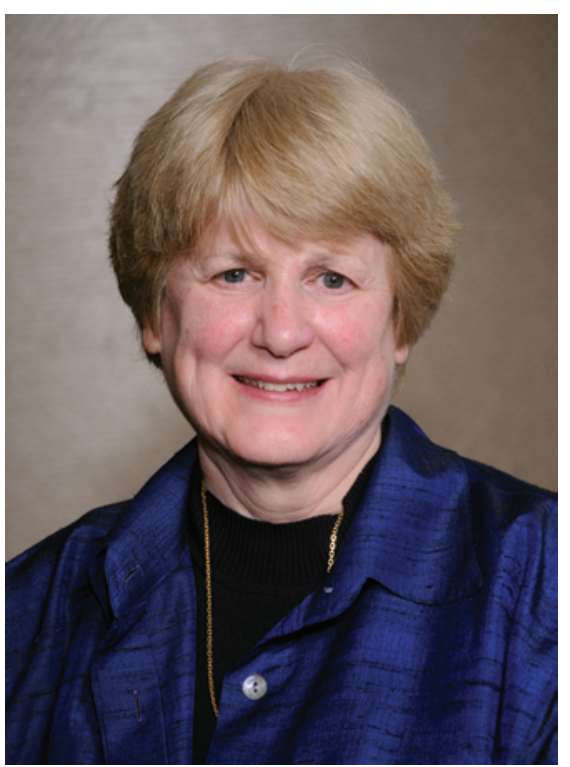

Figure 1. Mary-Claire King is the winner of the 2014 Lasker Koshland Special Achievement Award in Medical Science for bold and imaginative contributions to medical science and society. Her achievements include the discovery of the relationship between $B R C A 1$ and a hereditary form of breast cancer and the use of genetics to reunite missing persons with their families.

affected by breast cancer. Beginning her research in 1974, Dr. King found that the phenomenon of familial breast cancer had been recognized for more than 100 years (3), but modern epidemiological methods were only just beginning to be applied to the disease (Figure 2 and refs. 4-6). The risk of breast cancer was clearly greater for women with sisters or mothers affected by the disease, particularly if it was diagnosed prior to menopause and occurred in both breasts.
Because there was no evidence for shared lifestyle factors or environmental exposures that could account for the disease pattern, Dr. King hypothesized that a genetic mutation was at least partially responsible for some forms of familial breast cancer.

\section{The beginning of a} decades-long search

Dr. King approached the problem of identifying a genetic linkage in breast cancer with the mathematical modeling tools used in population and evolutionary genetics. In the early 1980s, epidemiologists from the National Cancer Institute's Surveillance, Epidemiology, and End Results Program interviewed 1,579 breast cancer patients under age 55 to determine whether other family members also had breast or ovarian cancer. Dr. King and her colleagues analyzed breast and ovarian cancer patterns in these families by multivariate, complex segregation analysis, a mathematical modeling technique used to determine whether a gene underlies the distribution of a phenotypic trait. The analysis was complicated by the fact that breast cancer in most families was unlikely to have an inherited component, and families with multiple affected members could have both inherited and noninherited cases. The analysis demonstrated that familial clustering could be explained by the inheritance of an autosomal dominant, highly penetrant susceptibility allele. Dr. King estimated that inherited susceptibility affected $4 \%$ of families in the study and that women carrying the susceptibility allele had a lifetime risk of developing breast cancer of $82 \%$, compared with $8 \%$ in the general population (7). Having demonstrated the possibility of a genetic link to breast cancer, the next step was to locate the responsible gene.

\section{Uncharted territory}

In the mid-1970s, when Dr. King began working on early-onset familial breast cancer, establishing a genetic link was an “incredibly hard problem": PCR would not 


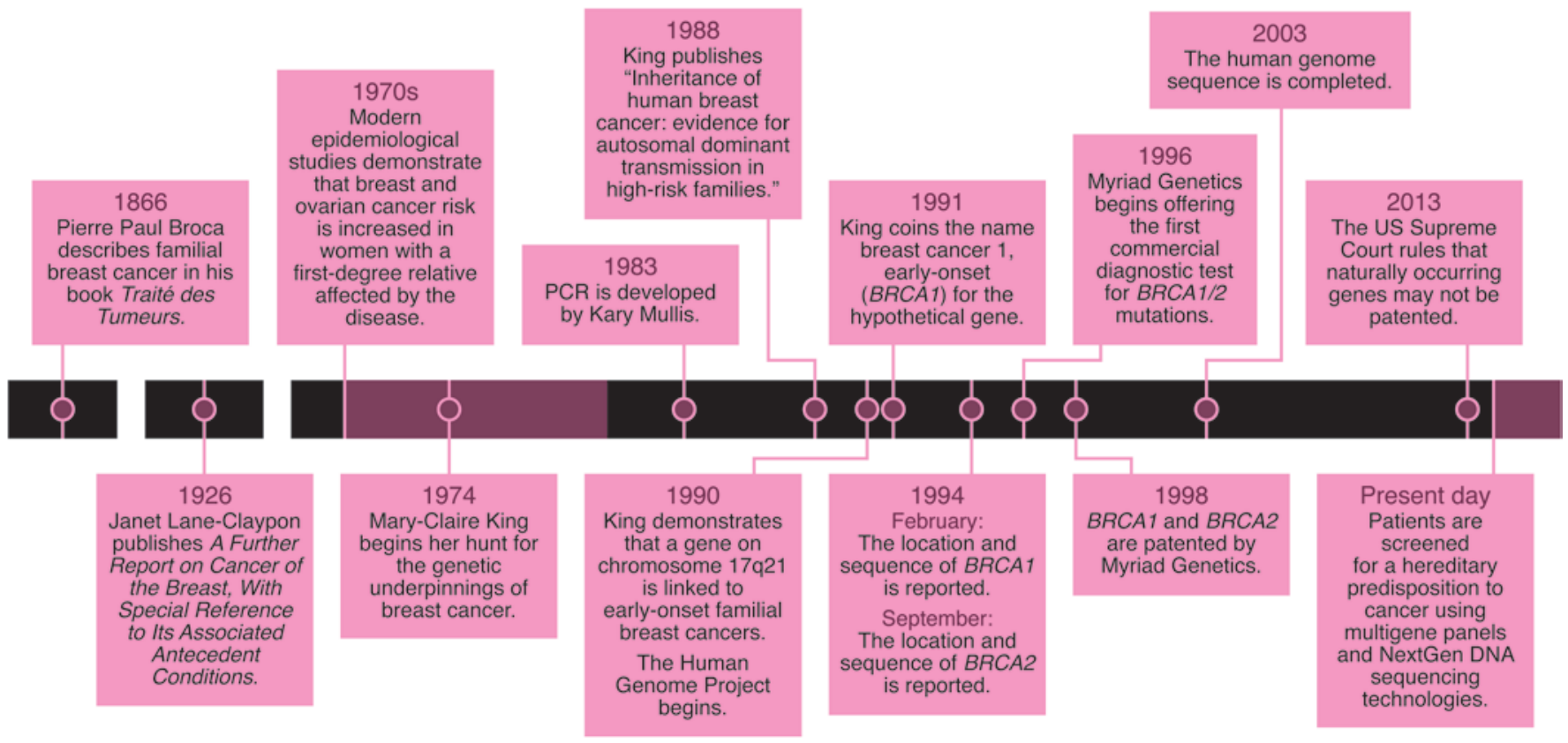

Figure 2. A timeline of the search for the genetic underpinnings of early-onset familial breast cancer. The French physician Pierre Paul Broca was the first to describe inherited breast cancer in 1866 (3), but modern epidemiological techniques were first applied to the disease by Janet Lane-Claypon in 1926 (4). In 1988, Dr. King demonstrated that some forms of early-onset familial breast cancer are heritable (7); in 1990, she showed that some heritable breast cancers are linked to a gene found on chromosome 17q21 (9). BRCA1 was cloned and sequenced by a group lead by Mark Skolnick of Myriad Genetics in 1994 (15). The first commercial test for mutations in BRCA1 and BRCA2 was brought to market in 1996. In 2013, the Supreme Court ruled that, as products of nature, genes could not be patented (18). Today, multigene panels and improved sequencing technologies allow patients to be screened for all cancerpredisposing mutations. Twenty years after it was cloned, the functions of BRCA1 in cell biology and cancer are still being elucidated.

be invented until 1983 (8), DNA sequencing was not yet possible, and genome was not yet a word (Figure 2). While Dr. King and her colleagues were analyzing genetic data, they also began trying to locate a chromosomal region that might be the home for the hypothetical gene using linkage analysis. Linkage analysis requires the creation of linkage maps, which are based on the frequencies of recombination between known genetic markers during the crossover of homologous chromosomes. A greater frequency of recombination between two markers indicates a greater distance between them.

Dr. King - by then an assistant professor at UC Berkeley - and her colleagues recruited 23 extended families consisting of 329 relatives with 146 cases of invasive breast cancer. In order to ensure that they were analyzing a heritable form of breast cancer, they selected for families that had breast cancers characterized by younger age at diagnosis, frequent occurrence of bilateral disease, and increased frequency of disease in male family members. Using blood samples from each family member, Dr. King and colleagues genotyped 173 different markers, mostly with Southern blotting, and for each family computed the likelihood of coinheritance of breast cancer with each marker. After stratifying the families by age of diagnosis, they found a region on chromosome 17q21 for which the likelihood of coinheritance with breast cancer in families with early-onset breast cancer was more than a million to one (9). Once Dr. King presented her results at the American Society of Human Genetics meeting in October 1990, the race was on to clone and sequence the actual gene (10).

\section{Tracking down BRCA1}

DNA sequencing and cloning were no easy feat in the early 1990s. The Human Genome Project officially began in 1990; essentially nothing was known about the human genome, which meant that other than chromosomal location, there was very little information available to guide researchers trying to find the gene linked to early-onset familial breast cancer, which Dr. King dubbed BRCA1 in 1991 (11).

Dr. King's lab, in collaboration with research teams led by Anne Bowcock, Francis Collins, and Jeff Boyd, developed a multipronged strategy to locate BRCA1 by: (a) continuing to performing linkage analysis to narrow the region of chromosome 17 that was likely to contain BRCA1; (b) using overlapping DNA clones to create a map of the locus (a technique known as chromosome walking); (c) creating a cDNA library of genes expressed in their tissue of interest and comparing the cDNAs with genes expressed in breast cancer patients; and (d) hybridizing those genes to clones from the region of interest in chromosome 17 (11). Although they did not realize it at the time, the region that Dr. King and her collaborators were trying to map was nearly 22 million bp in length and was characterized by architectural features that made mapping even more difficult. The DNA clones they used to map this region were in the form of cosmids (40 kb) and yeast artificial chromosomes (100-200 kb). The work was painstakingly slow and difficult, but also highly competitive. In addition to Dr. King and her colleagues, multiple research groups around the world were working as quickly as they could to locate and sequence BRCA1.

In February 1994, a team of researchers led by Mark Skolnick at Myriad Genetics, in conjunction with collaborators at the 
NIH, sequenced BRCA1 (12). A follow-up study in October revealed multiple different mutations, one in each family, that predisposed carriers to breast and ovarian cancer, including a 1-bp insertion, a premature stop codon, and 11-bp deletion, a missense mutation, and a putative regulatory mutation (13). In September 1994, Michael Stratton and Richard Wooster mapped BRCA2 by linkage analysis on chromosome 13 (14), setting off a race to clone this sister gene as well, a race in which Dr. King was not involved. Myriad Genetics was awarded patents on both BRCA1 and BRCA2 in $1998(15,16)$. Based on their patent, the company began offering commercial testing for hereditary breast and ovarian cancer susceptibility in 1996 (17). These patents were invalidated in June 2013, when the US Supreme Court ruled that naturally occurring genes may not be patented (18).

Even though Dr. King and her colleagues did not win the race to clone BRCA1, her work completely shifted the view of the role of genes in cancer. In an interview with the University of Washington alumni magazine, Columns, her colleague Maynard Olson explained that prior to Dr. King's discovery, “... there was a widespread view that diseases like breast cancer were caused by multiple genes that interact with environmental factors. This didn't provide geneticists with a clear road ahead ... . [Dr. King's findings] told a different story: that in carefully selected families she could find a fairly simple genetic link for breast cancer. It provided us with a powerful path forward. We now know that many important diseases can be attacked in the same way" (19).

\section{Viewing cancer through the lens of genetics}

Twenty years after the cloning of $B R C A 1$ and $B R C A 2$, we know that both genes are tumor suppressors that have nonoverlapping functions in a variety of cellular activities, including DNA repair, homologous recombination, transcriptional regulation, and protein degradation (20, 21). Both BRCA1 and BRCA2 have functional relationships with at least ten other genes that can harbor breast cancer-associated mutations, including TP53, ATM, CHEK2, and PALB2 $(22,23)$. Despite the intensive research focus on these two genes, the roles of $B R C A 1$ and $B R C A 2$ in cell biology and cancer are still being elucidated.

Thousands of different mutations have now been identified in $B R C A 1$ and $B R C A 2$ (24). Hereditary breast and ovarian cancer is caused by germline loss-of-function mutations in either $B R C A 1$ or $B R C A 2$; more than $60 \%$ of women carrying a $B R C A 1$ mutation and around $45 \%$ of women with a BRCA2 mutation will develop breast cancer before age 70 , while the risk of ovarian cancer in these women is close to $40 \%$ and $25 \%$, respectively (25). Because of the significant increase in lifetime risk of breast and ovarian cancer associated with these mutations, more than a million individuals with a familial history of breast cancer have undergone genetic screening (24). Moreover, screening for mutations in $B R C A 1$ and $B R C A 2$ has served as a model for integrating genetics and medicine. It is now possible to screen simultaneously for all cancer-predisposing mutations, enabling clinicians to identify patients who could benefit from additional screening, surveillance, and prophylactic treatments. Dr. King has been instrumental in devising strategies for patient screening, including the use of massively parallel, next-generation sequencing technologies that allow for the screening of multiple genes in a cost-effective manner. The test, known as BROCA, provides comprehensive testing for all known inherited breast cancer gene mutations (26-29).

\section{Using genomic technologies to investigate human rights abuses}

Dr. King has also used genomic tools to aid in the investigation of human rights abuses. In Argentina between 1975 and 1983, a period known as the Dirty War, an estimated 15,000-30,000 suspected political dissidents were "disappeared" by the ruling military junta. Many of their children disappeared as well; other children were born to their imprisoned pregnant mothers. Instead of being returned to their families, the children were taken into the households of members of the military and other junta sympathizers. The Abuelas de Plaza de Mayo was formed by the relatives of the disappeared to demand the return of the more than 400 children kidnapped by the military junta. To do so, the grandmothers needed to identify who the children were (30). The Abuelas de Plaza de Mayo asked the American Association for the Advancement of Science to provide a geneticist who could help identify their missing grandchildren. In 1984, Dr. King began working with the Abuelas de Plaza de Mayo to provide evidence of kinship. Using human lymphocyte antigens (HLAs) and other genetic markers, Dr. King first calculated an "index of grandpaternity" to determine the probability that a child was related to a grandparent (31). In December 1984, Paula Logares became the first child to be reunited with her biological family based on Dr. King's genetic evidence (32).

Because HLA markers do not vary enough between people to guarantee an exact match, samples from multiple relatives are required to accurately confirm kinship. Unfortunately, in many cases, there were few surviving relatives. In order to address these problems, Dr. King pioneered the use of mitochondrial DNA (mtDNA) sequencing for identification (33-35). Sequencing of mtDNA had several advantages: (a) the control region near the origin of replication is highly diverse among individuals; (b) mtDNA is passed down only through the matrilineal line; (c) mtDNA is relatively abundant; and (d) if matching must be to remains, rather than to living persons, mtDNA can be extracted from a variety of tissues, including teeth, in which DNA is well preserved. Using this technology, Dr. King and her lab later worked with the United Nations War Crimes Tribunal to identify victims of human rights abuses from Cambodia, Guatemala, El Salvador, Rwanda, Ethiopia, and Bosnia and with the US military and the UN to identify the remains of soldiers missing in action.

\section{Shaping the future of genomics} Dr. King is currently a Professor of Genome Sciences and Medicine at the University of Washington. She continues to investigate the genetic underpinnings of human diseases, including cancer, deafness, and schizophrenia, as well as the environmental factors that influence these genes (36-42). Dr. King is also involved in the Human Genome Diversity Project, a worldwide collaboration among scientists who use genetics to understand human migration patterns and evolution $(43,44)$. 
In her 2012 presidential address to the American Society for Human Genetics, Dr. King outlined three thoughts that have guided her approach to science: "the most important questions come from people on the frontlines, the most righteous projects demand the most rigorous science, and no question is too big to ask" (1). As a scientist who has chosen to work on problems that have a profound impact on her fellow human beings, Dr. King has revolutionized our understanding of the role of genes in human disease, as well as the treatment of cancer, through the discovery of BRCA1. Her use of genomic technology to identify missing people has reunited families and provided evidence of human rights abuses. Both of these achievements are characterized by an ability to take on seemingly insurmountable problems and to solve them with a combination of creativity and hard work. The work of Dr. King has expanded the bounds of genomics to enhance both human health and human rights.

\section{Jillian H. Hurst}

1. King MC. 2012 Presidential Address: The scientist as a citizen of the world. Am J Hum Genet. 2013;92(3):319-322

2. King MC, Wilson AC. Evolution at two levels in humans and chimpanzees. Science. 1975;188(4184):107-116.

3. Broca P. Traité des Tumeurs. Paris, France: P. Asselin; 1866.

4. Lane-Claypon JE. A Further Report on Cancer of the Breast, With Special Reference to Its Associated Antecedent Conditions. London, United Kingdom: His Majesty's Stationary Office; 1926.

5. Kelsey JL. A review of the epidemiology of human breast cancer. Epidemiol Rev. 1979;1:74-109.

6. Press DJ, Pharoah P. Risk factors for breast cancer: a reanalysis of two case-control studies from 1926 and 1931. Epidemiol Camb Mass. 2010;21(4):566-572.

7. Newman B, Austin MA, Lee M, King MC. Inheritance of human breast cancer: evidence for autosomal dominant transmission in high-risk families. Proc Natl Acad Sci U S A. 1988;85(9):3044-3048.

8. Mullis KB, Faloona FA. Specific synthesis of DNA in vitro via a polymerase-catalyzed chain reaction. Methods Enzymol. 1987;155:335-350.

9. Hall JM, et al. Linkage of early-onset familial breast cancer to chromosome 17q21. Science. 1990;250(4988):1684-1689.

10. Davies K. Breakthrough: The Race To Find The
Breast Cancer Gene. New York, New York, USA: Wiley and Sons; 1996.

11. King MC. "The race" to clone BRCA1. Science. 2014;343(6178):1462-1465.

12. Goldgar DE, et al. A large kindred with 17q-linked breast and ovarian cancer: genetic, phenotypic, and genealogical analysis. J Natl Cancer Inst. 1994;86(3):200-209.

13. Miki Y, et al. A strong candidate for the breast and ovarian cancer susceptibility gene BRCA1. Science. 1994;266(5182):66-71.

14. Wooster R, et al. Localization of a breast cancer susceptibility gene, BRCA2, to chromosome 13q12-13. Science. 1994;265(5181):2088-2090.

15. Skolnick MH, et al., inventors; Myriad Genetics, Inc., University of Utah Research Foundation, Secretary of Health Human Services, assignees. 17Q-linked breast ovarian cancer susceptibility gene. US patent 5,747,282. May 5, 1998.

16. Tavtigian SV, Kamb A, Simard J, Couch F, Rommens JM, Weber BL. Chromosome 13-linked breast cancer susceptibility gene. US patent 5,837,492. November 17, 1998.

17. Williams-Jones B. History of a gene patent: tracing the development and application of commercial BRCA testing. Health Law J. 2002;10:123-146.

18. Association for Molecular Pathology v Myriad Genetics, 569 US 12-398 (2013).

19. McHale L. Putting the puzzle together: in the jigsaw world of human genetics, UW professor Mary-Claire King found a crucial piece that helps solve the mystery of breast cancer. University of Washington Alumni Association Web site: http://www.washington.edu/alumni/columns/ sept96/king1.html. Accessed August 18, 2014.

20. Welcsh PL, Owens KN, King MC. Insights into the functions of BRCA1 and BRCA2. Trends Genet. 2000;16(2):69-74.

21. Venkitaraman AR. Cancer suppression by the chromosome custodians, BRCA1 and BRCA2. Science. 2014;343(6178):1470-1475.

22. Walsh T, et al. Spectrum of mutations in BRCA1, BRCA2, CHEK2, and TP53 in families at high risk of breast cancer. JAMA. 2006;295(12):1379-1388.

23. Walsh T, King MC. Ten genes for inherited breast cancer. Cancer Cell. 2007;11(2):103-105.

24. Couch FJ, Nathanson KL, Offit K. Two decades after BRCA: setting paradigms in personalized cancer care and prevention. Science. 2014;343(6178):1466-1470.

25. Chen S, Parmigiani G. Meta-analysis of BRCA1 and BRCA2 penetrance. J Clin Oncol. 2007;25(11):1329-1333.

26. Walsh T, et al. Detection of inherited mutations for breast and ovarian cancer using genomic capture and massively parallel sequencing. Proc Natl Acad Sci U S A. 2010;107(28):12629-12633.

27. Walsh $\mathrm{T}$, et al. Mutations in 12 genes for inherited ovarian, fallopian tube, and peritoneal carcinoma identified by massively parallel sequencing. Proc Natl Acad Sci US A. 2011;108(44):18032-18037.
28. Nord AS, Lee M, King M-C, Walsh T. Accurate and exact $\mathrm{CNV}$ identification from targeted high-throughput sequence data. BMC Genomics. 2011;12:184.

29. Metzker ML. Sequencing technologies - the next generation. Nat Rev Genet. 2010;11(1):31-46.

30. Penchaszadeh VB. Genetic identification of children of the disappeared in Argentina. J Am Med Womens Assoc. 1997;52(1):16-21.

31. Di Lonardo AM, Darlu P, Baur M, Orrego C, King MC. Human genetics and human rights. Identifying the families of kidnapped children. Am J Forensic Med Pathol. 1984;5(4):339-347.

32. Guest I. Behind The Disappearances: Argentina's Dirty War Against Human Rights And The United Nations. Philadelphia, Pennsylvania, USA: University of Pennsylvania Press; 1990

33. Owens KN, Harvey-Blankenship M, King MC. Genomic sequencing in the service of human rights. Int J Epidemiol. 2002;31(1):53-58.

34. King MC. An application of DNA sequencing to a human rights problem. Mol Genet Med. 1991;1:117-131.

35. Ginther C, Issel-Tarver L, King MC. Identifying individuals by sequencing mitochondrial DNA from teeth. Nat Genet. 1992;2(2):135-138.

36. Pritchard CC, et al. Validation and implementation of targeted capture and sequencing for the detection of actionable mutation, copy number variation, and gene rearrangement in clinical cancer specimens. J Mol Diagn JMD. 2014;16(1):56-67.

37. Rippey C, et al. Formation of chimeric genes by copy-number variation as a mutational mechanism in schizophrenia. Am J Hum Genet. 2013;93(4):697-710.

38. Pierce SB, et al. Mutations in LARS2, encoding mitochondrial leucyl-tRNA synthetase, lead to premature ovarian failure and hearing loss in Perrault syndrome. Am J Hum Genet. 2013;92(4):614-620.

39. Roeb W, Higgins J, King MC. Response to DNA damage of CHEK2 missense mutations in familial breast cancer. Hum Mol Genet. 2012;21(12):2738-2744.

40. Brownstein Z, et al. Targeted genomic capture and massively parallel sequencing to identify genes for hereditary hearing loss in Middle Eastern families. Genome Biol. 2011;12(9):R89.

41. Nord AS, et al. Reduced transcript expression of genes affected by inherited and de novo CNVs in autism. Eur J Hum Genet. 2011;19(6):727-731.

42. Casadei $S$, et al. Contribution of inherited mutations in the BRCA2-interacting protein PALB2 to familial breast cancer. Cancer Res. 2011;71(6):2222-2229.

43. Lipovich L, King MC. Abundant novel transcriptional units and unconventional gene pairs on human chromosome 22. Genome Res. 2006;16(1):45-54.

44. King M-C, Motulsky AG. Human genetics. Mapping human history. Science. 2002;298(5602):2342-2343. 